\title{
Rare Typhoon Development Near the Equator
}

\author{
C.-P. Chang \\ Department of Atmospheric Sciences \\ National Taiwan University, Taipei, Taiwan, ROC \\ Department of Meteorology \\ Naval Postgraduate School, Monterey, California, USA \\ cpchang@nps.edu \\ Teo Suan Wong \\ Meteorological Services Division \\ National Environment Agency, Republic of Singapore
}

Received 15 August 2007

Revised 19 January 2008

Accepted 22 January 2008

\begin{abstract}
The formation of Typhoon Vamei on 27 December 2001 in the southern South China Sea was the first-observed tropical cyclogenesis within 1.5 degrees of the equator. This rare event was first detected by observations of typhoon strength winds from a US navy ship, and the existence of an eye structure was confirmed by satellite and radar imageries. This paper reviews these observations, and discusses the dynamic theory that may explain the process suggested by Chang et al. (2003) in which a strong cold surge event interacting with the Borneo vortex led to the equatorial development. As pointed out by Chang et al., the most intriguing question is not how Vamei could form so close to the equator, but is why such a formation was not observed before then.
\end{abstract}

\section{Introduction}

One of the generally accepted conditions for tropical cyclone formation has been that the location is "away from the equator." This condition is based on the lack of Coriolis effect at the equator, and supported by observations over more than a century that show most tropical cyclogeneses to occur poleward of $5^{\circ}$ latitude (Gray, 1968; McBride, 1995). The previous record was set by Typhoon Sarah in 1956 at $3.3^{\circ} \mathrm{N}$ (Fortner, 1958). Typhoon Vamei formed at $1.5^{\circ} \mathrm{N}$ at the southern tip of the South China Sea at 00 UTC 27 December 2001, a latitude that most textbooks (e.g. Anthes, 1982) ruled out for development. The cyclone was named by the Japan Meteorological Agency, which initially identified it as a tropical storm with estimated winds of $21 \mathrm{~ms}^{-1}$. It was upgraded to a typhoon by the Joint Typhoon Warning Center (JTWC) in Hawaii. Figure 1 shows the best track and intensity of Vamei, published by the JTWC. The storm made landfall over southeast Johor at the southern tip of Peninsular Malaysia, about $50 \mathrm{~km}$ northeast of Singapore, at 0830 UTC 27 December 2001. Upon making landfall, it weakened rapidly to a tropical depression. It continued in its west-northwest track across southern Johor, the Malacca 


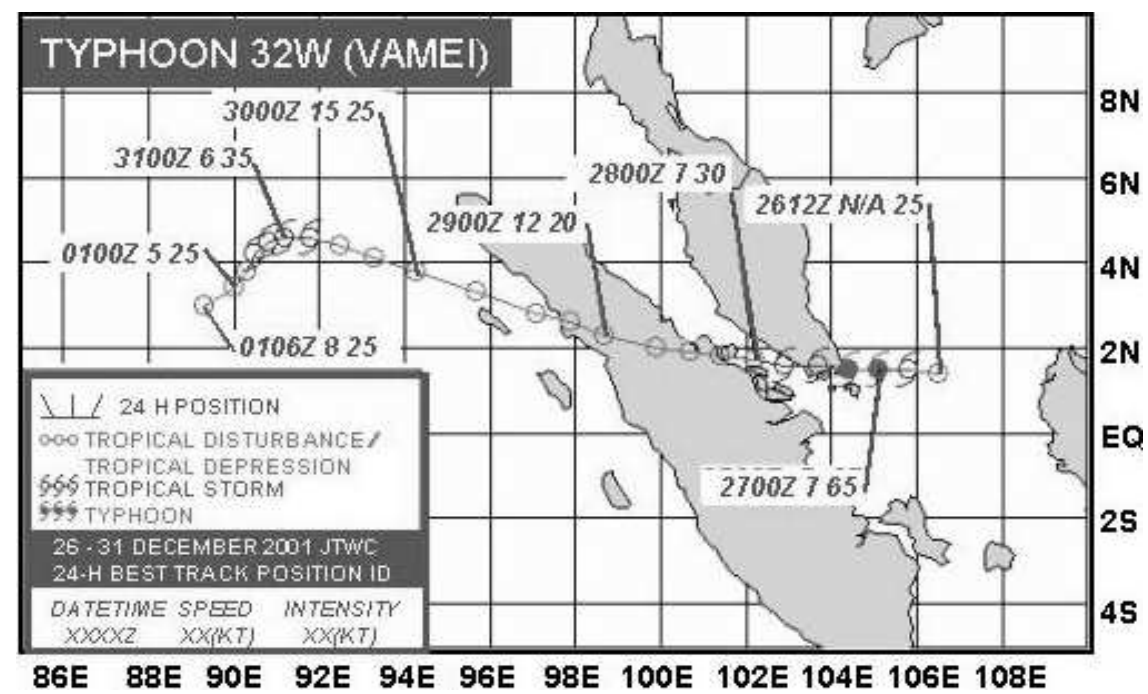

Figure 1. Best track and intensity of Vamei from 1200 UTC 12 December 2001 to 00 UTC 1 January 2002. (Diagram courtesy of JTWC.)

Straits, and made landfall again in Sumatra. Upon entering the Bay of Bengal, the storm regenerated and continued in its northwest track before dissipating in the central Bay of Bengal on 31 December 2001. During the short period of $12 \mathrm{~h}$ as a typhoon and another $12 \mathrm{~h}$ as a tropical storm, Vamei caused damage to two US Navy ships, including a carrier, and flooding and mudslides in southern Peninsular Malaysia's Johor and Pahang states. More than 17,000 people were evacuated and 5 lives were lost.

The upgrade of Vamei to the typhoon category by the JTWC was based mainly on the shipboard observations from several US Navy ships within the small eyewall, with reports of sustained winds of $39 \mathrm{~m} \mathrm{~s}^{-1}$ and gusts of up to $54 \mathrm{~m} \mathrm{~s}^{-1}$. Because of its equatorial latitude, there was considerable interest among tropical cyclone forecasters regarding the typhoon's structure and the process of its development. This article will review the relevant data used to observe the development of Typhoon Vamei and discuss some theoretical considerations regarding its possible formation mechanism.

\section{Background Flow and the Observed Development}

Vamei developed in late December 2001, near the middle of the Asian winter monsoon season, which is characterized by strong baroclinicity in the middle latitudes and northeasterly winds at lower levels. Freshening of the northeasterly winds, or cold surges (Chan and $\mathrm{Li}$, 2004; Chang et al., 2004, 2005), occur sporadically and spread equatorward. Although cold surge winds are typically dry, they are moistened by the over-water trajectory (Johnson and Houze, 1987) and have been associated with increased deep convection and enhanced uppertropospheric outflow over the Maritime Continent, which is related to an enhanced East Asian local Hadley cell (Lau and Chang, 1987). The cold surge air can reach the equator in about two days (Chang et al., 1983). Conservation of potential vorticity causes the air to turn eastward after it crosses the equator. These Southern Hemisphere equatorial westerlies may enhance the Australian monsoon trough farther south, between $10^{\circ} \mathrm{S}$ and $20^{\circ} \mathrm{S}$, where tropical 
cyclogenesis occurs frequently (e.g. Holland, 1984; McBride, 1995).

Synoptic-scale disturbances are also found to occur in the vicinity of the island of Borneo (Johnson and Houze, 1987; Chang et al., 2005). Over this region, the low-level basic-state background vorticity is cyclonic, due to the mean northeasterly wind maximum over the South China Sea and the equatorial westerlies associated with the Asian winter monsoon. Therefore, perturbations in this basic state often amplify into synoptic-scale cyclonic circulations. These disturbances are often found southeast of the primary region of cold surge northeasterly winds. Often, the circulation is present as a quasi-stationary, low-level cyclonic circulation, which is a persistent feature of the boreal winter climatology (Johnson and Houze, 1987; Chang et al., 2005). Although the circulation may not be completely closed on the east side over the island, it has been referred to as the Borneo

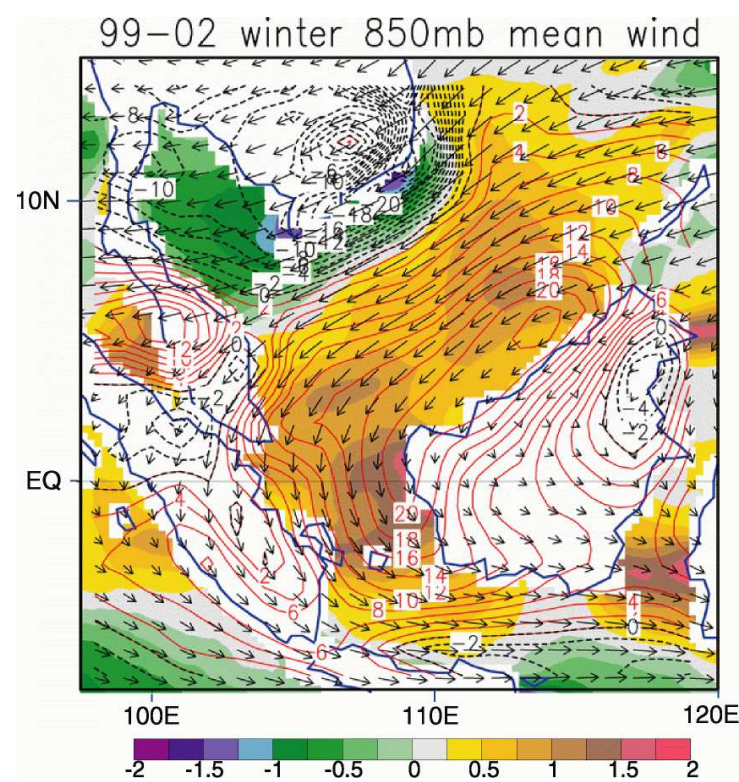

Figure 2. 1999/2000-2001/2002 boreal winter (DJF) mean of $850 \mathrm{hPa}$ NOGAPS $1^{\circ} \times 1^{\circ}$ wind and vorticity (contours: solid - positive; dashed - negative; interval $\left.2 \times 10^{-5} \mathrm{~s}^{-1}\right)$, and surface vorticity based on $25 \mathrm{~km}$ resolution QuikSCAT winds (yellow - positive; green - negative). [Diagram from Chang et al. (2003) by permission of American Geophysical Union.] vortex (Chang et al., 2004, 2005). The mean location of the vortex along the northwest coast of Borneo may be seen in Fig. 2, which shows the $1999 / 2000-2001 / 2002$.

December-February mean $850 \mathrm{hPa}$ vorticity from the $1^{\circ} \times 1^{\circ}$ Navy Operational Global Atmospheric Prediction System (NOGAPS) analysis, overlaid with the surface vorticity derived from the QuikSCAT satellite scatterometer winds. The Borneo vortex is often associated with deep convection and intense latent heat release, and upper-level divergence is often present. However, because most of the time a significant part of the vortex circulation is over land (Fig. 3), even when a vortex drifts to northern Borneo between $5^{\circ} \mathrm{N}$ and $7^{\circ} \mathrm{N}$, which are latitudes considered more favorable for tropical cyclone development, it is very difficult for the vortex to develop into a tropical cyclone (Chang et al., 2003).

Chang et al. (2003) provided the following description of the synoptic events preceding the development of Vamei. Starting from 19 December 2001, a cold surge developed rapidly over the South China Sea while the center

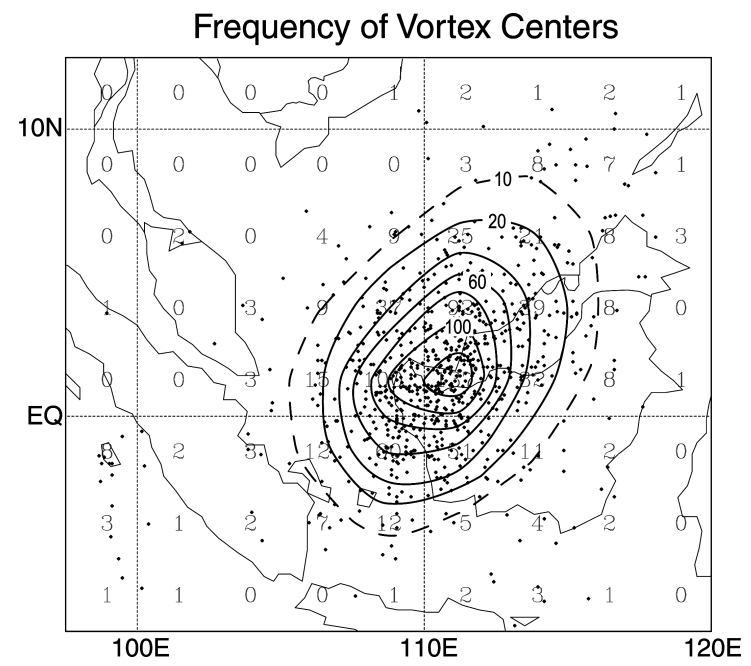

Figure 3. Analyzed Borneo vortex center locations based on streamlines of unfiltered $925 \mathrm{hPa}$ winds. (NCEP/NCAR reanalysis winds at $925 \mathrm{hPa}$ at $2.5^{\circ} \times 2.5^{\circ}$ grids, for 21 boreal winters (December 1980 February 2001.) [Diagram from Chang et al. (2005) by permission of American Meteorological Society.] 


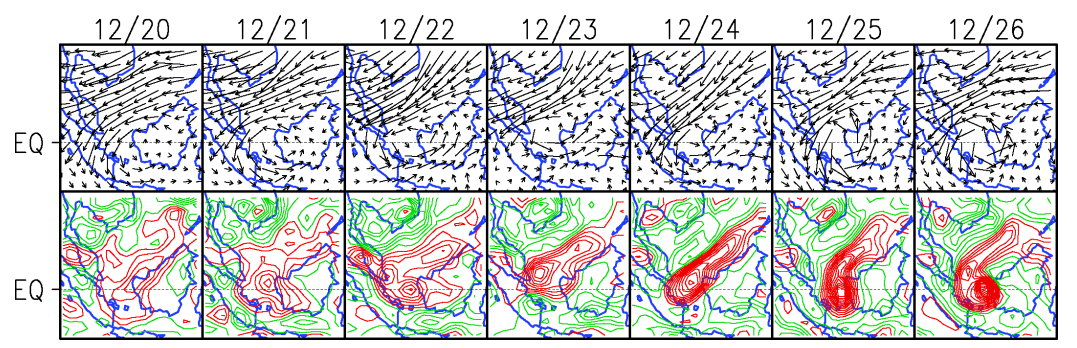

Figure 4. NOGAPS $1^{\circ} \times 1^{\circ} 850 \mathrm{hPa}$ wind and vorticity (red - positive; green - negative) at 00 UTC 20-26 December 2001.

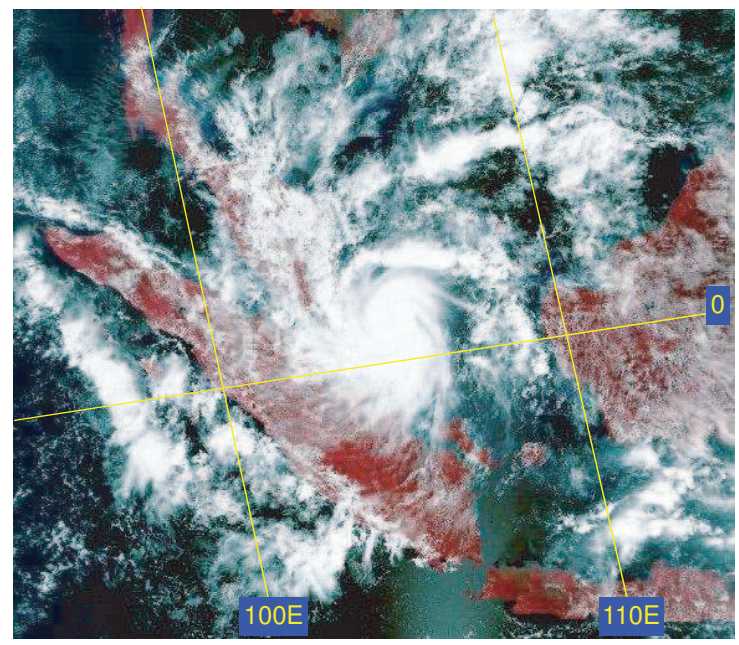

Figure 5. MODIS satellite image on 27 December 2001, showing Typhoon Vamei near Singapore. (Diagram courtesy of Professor Lim Hock, National University of Singapore.)

of the Borneo vortex was located near $3^{\circ} \mathrm{N}$ on the northwest coast (not shown). The 850 $\mathrm{hPa}$ NOGAPS wind analysis and vorticity in Fig. 4 depict the southwestward movement of the vortex from along the Borneo coast toward the equator. By 21 December, the center of the vortex had moved off the coast over water, where the open sea region at the southern end of the South China Sea narrows to about $500 \mathrm{~km}$, with Borneo to the east and the Malay Peninsula and Sumatra to the west. This over-water location continued for several days. While the vortex center remained in the narrow equatorial sea region, the strong northeasterly surge persisted, and was slightly deflected to the northwest of the vortex. This near "trapping" of the Borneo vortex by a sustained surge is unusual, because normally the vortex center would be pushed eastward by the strengthening surge that streaks southwestward in the middle of the South China Sea. Consequently, the cross-equatorial flow wrapped around the vortex and provided a background area of cyclonic relative vorticity with a magnitude of $>1 \times$ $10^{-5} \mathrm{~s}^{-1}$, which is comparable to that of the Coriolis parameter $5^{\circ}$ or more away from the equator.

Figure 5 shows the MODIS satellite image on 27 December 2001. Vamei's circulation center can be estimated to be just north of $1^{\circ} \mathrm{N}$, but an eye is not observable under the clouds. Even though the size of the typhoon is quite small, which is considered a special characteristic of low latitude TCs by some researchers 


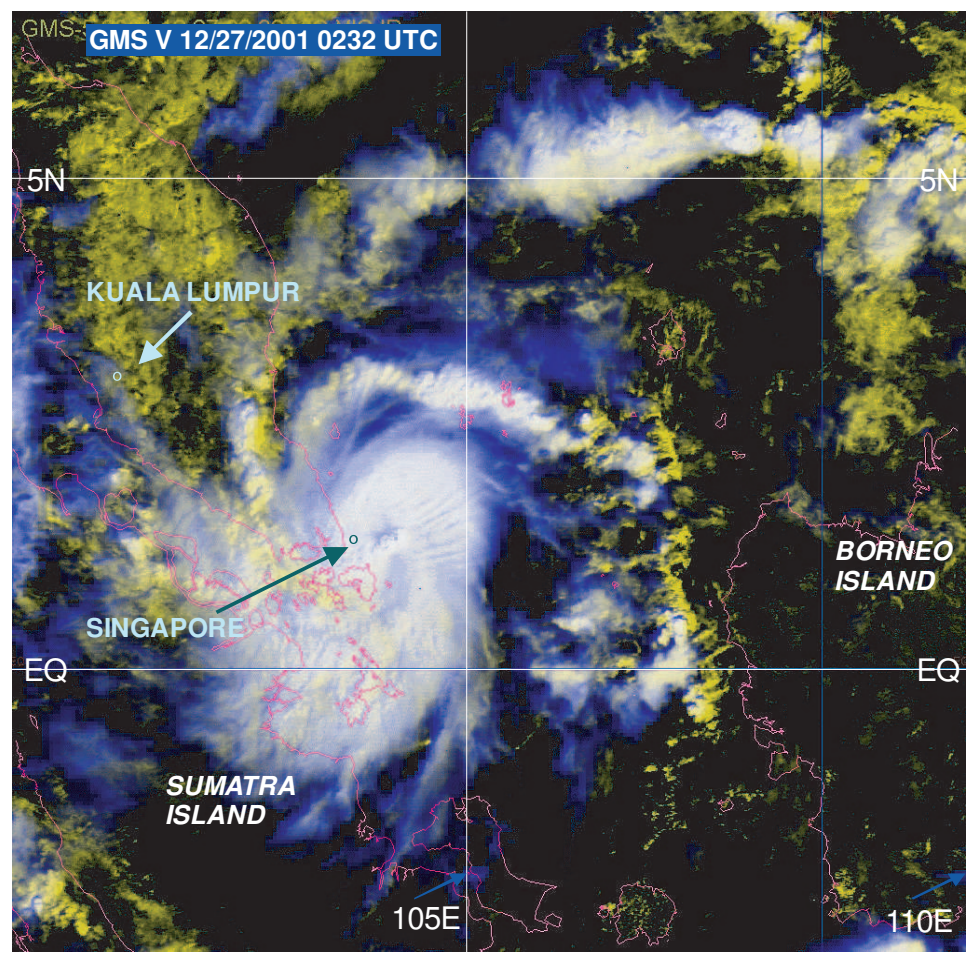

Figure 6. Japanese Geostationary Meteorological Satellite image at 0232 UTC 27 December 2001. All national weather services in the region reported it as a tropical storm.

(e.g. DeMaria and Pickle, 1988), the spiral cloud bands emanating out from around the center clearly indicate that the storm circulation was on both sides of the equator. Figure 6 shows the Japanese Geostationary Meteorological Satellite image at 0232 UTC of the same day. Feeder bands from both sides of the equator spiral into the center of Vamei, where a small eye is visible. An eye was also observed in TRMM and SSM/I images within the preceding two hours (not shown). The diameter of the eye estimated from different sensors ranges from $28 \mathrm{~km}$ to $50 \mathrm{~km}$. Vamei's small size as it formed at the southern end of the South China Sea made it difficult to observe its highest wind speed from groundbased observations or to estimate its intensity from satellite images. As a result, all national weather services in the region reported it as a tropical storm. Without the chance passage by the USS Carl Vinson carrier group through its eyewall, the JTWC may not be able to operationally upgrade the intensity of the storm to that of a typhoon either.

Figure 7 shows Doppler weather radar images from Singapore's Changi Airport during the 12 hours prior to the arrival of Vamei. The rapid development of the eye of Vamei can be readily seen in 3-hour intervals. The eye was just starting to form with an irregular boundary when the storm moved into radar range at 1930 UTC 26 December 2001 (right panel). It became quite well organized 3 hours later, at 2230 UTC (middle panel), with a geometric center of the eye near $1.4^{\circ} \mathrm{N}$. By 0130 UTC 27 December (left panel), the eye had become a nearly symmetric round feature.

Evidence of the strength of Vamei and its relationship with the cold surge can be revealed from QuickSCAT satellite scatterometer wind data. Figure 8 shows that the QuickSCAT wind 


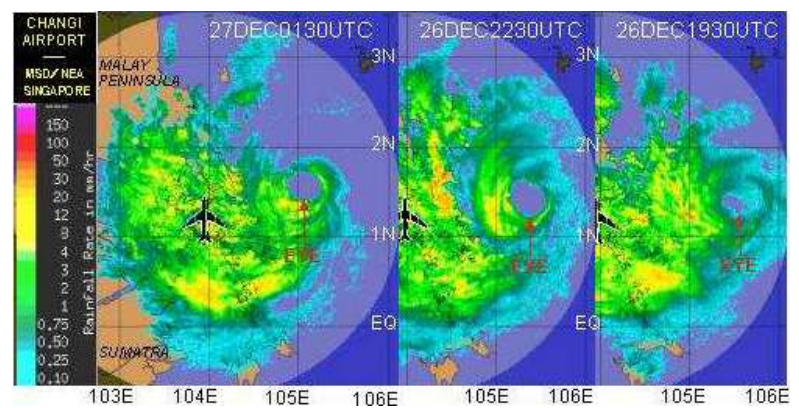

Figure 7. Changi Airport (Singapore) Doppler weather radar images (the color legend indicates estimated rain rates, in $\mathrm{mm} / \mathrm{h}$ ) in three-hour intervals, with the time sequence of the images organized from right to left: 1930 UTC 26 December (right panel), 2230 UTC (middle panel) and 0130 UTC 27 December (left panel).

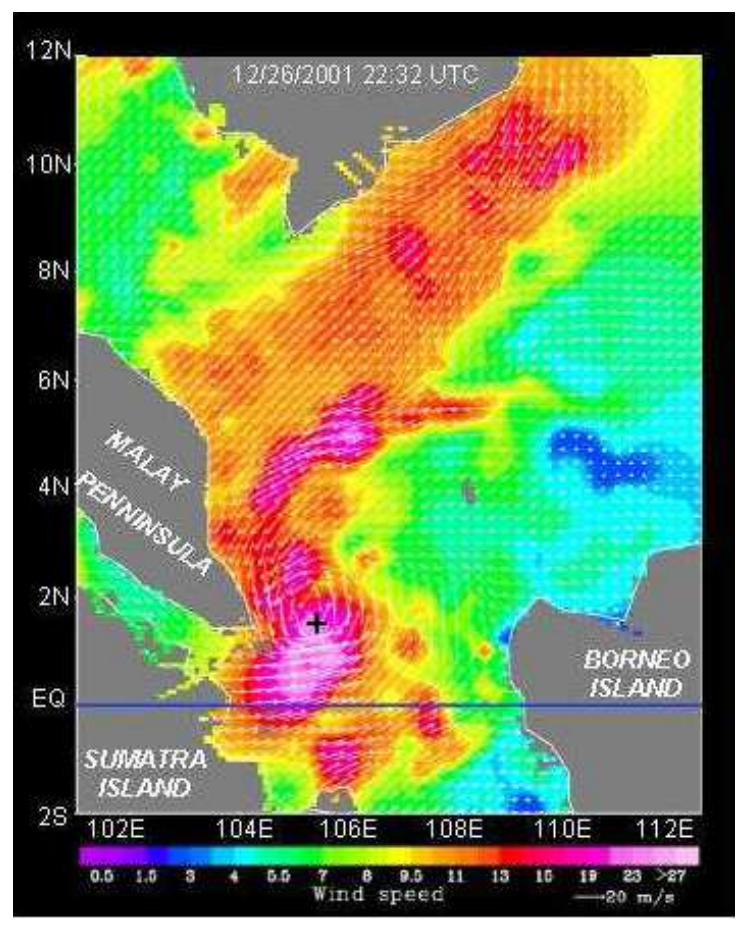

Figure 8. QuickSCAT satellite scatterometer wind direction and speed (color shading and arrow length) at 2232 UTC 26 December 2001, showing the typhoon strength of Vamei and the remnant of the continuing surge wind upstream in the northern South China Sea. See text for details. (Diagram courtesy of Jet Propulsion Laboratory/NASA.)

direction and speed at 2232 UTC 26 December 2001 captured both the signal of Vamei as it developed to typhoon strength, and the remnant of the continuing surge wind upstream in the northern South China Sea. At the southern perimeter, the wind speed at a $10 \mathrm{~m}$ height has already reached above $27 \mathrm{~ms}^{-1}$ over an area of about $1^{\circ}$ latitude $\times 1^{\circ}$ longitude. The northern spiral band extends to about $6^{\circ} \mathrm{N}$ and is detached from the cold surge wind belt further north.

\section{Roles of the Winter Monsoon and Possible Mechanisms}

Based on the synoptic sequence of the lowlevel circulations, Chang et al. (2003) suggested that Vamei formed as a result of an interaction between two prominent features of the Asian winter monsoon: a weak Borneo vortex that drifted into, and remained at, the southern tip of the South China Sea; and a strong and persistent cold surge that created the large background cyclonic vorticity at the equator.

A similar equatorial generation process was proposed two decades ago in the cold surge theory of Lim and Chang (1981), who used the framework of the equatorial beta-plane equatorial wave theory. In their barotropic theory, geostrophic adjustment and potential vorticity conservation following a cross-equatorial surge spin up counterclockwise rotation to the east of the surge axis, where in the real world the Borneo vortex is located. A comparison of Lim and Chang's cold surge theory and the observed low-level flow during the development 
EQUATORIAL WAYE THEORY
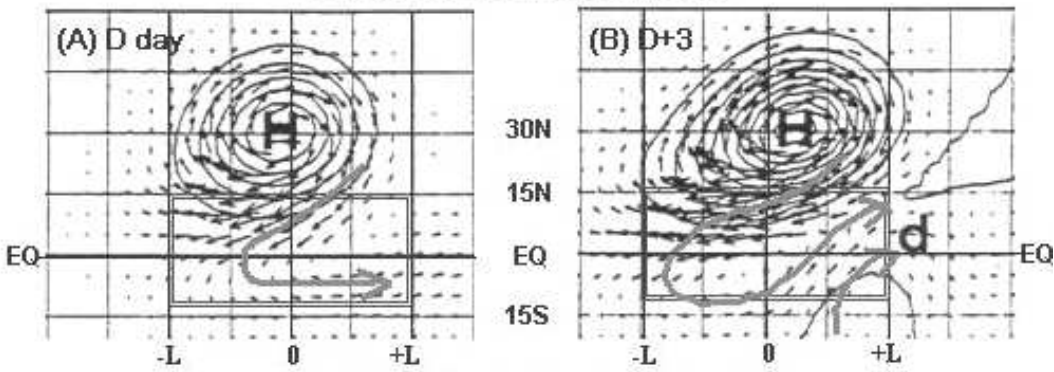

NOCAP8 850 HPA WIND ANALYSES
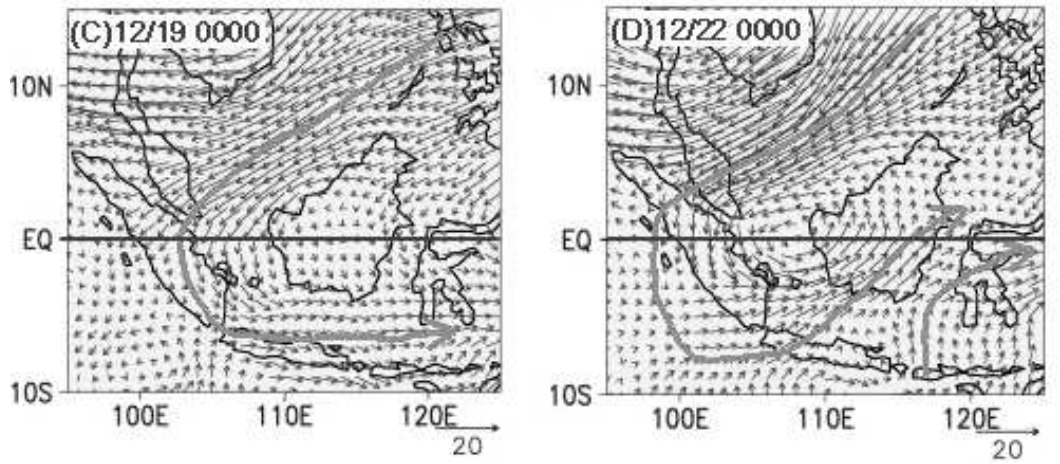

Figure 9. Comparison of Lim and Chang's (1981) barotropic equatorial beta-plane cold surge theory (panels A and B) and observed NOGAPS $850 \mathrm{hPa}$ wind analysis (panels C and D), each for two time periods separated by three days. Because the narrow width of the South China Sea confined the width of the intense surge belt to about one half of that in the terrain-free equatorial beta-plane solution, a comparison of the theory and the actual development may be made by scaling the east-west dimension of the upper panels to one half of the original size $\left(\mathrm{L}=15^{\circ}\right.$ longitude instead of $30^{\circ}$ ), or treating the highlighted rectangular area in panels $\mathrm{A}$ and $\mathrm{B}$ as being comparable to the domain of the NOGAPS plots. The location of the high center in panel B was also shifted eastward by $0.4 \mathrm{~L}$ to account for the reduced zonal scale, the typical eastward movement of the East Asian surface high center, and the geographical restriction of the surge belt by the South China Sea. See text for details. [Diagram adapted from Lim and Chang (1980) and Chang et al. (2003) by permission of American Meteorological Society and American Geophysical Union, respectively.]

of Typhoon Vamei is shown in Fig. 9, where the top panels (A and B) display the theoretical solutions three days apart in a pressureinduced surge, and the bottom panels $(\mathrm{C}$ and D) display the NOGAPS $850 \mathrm{hPa}$ wind analysis for 19 December and 22 December 2007, respectively.

Panel A shows the theoretical solution of a case of an equatorward surge that is initiated by a high-pressure anomaly centered at $30^{\circ} \mathrm{N}$, with no mean flow. The pattern resembles the typical cold surge event that follows the southeastward movement of an East Asian surface high center with the development of a northeast-southwest tilt. This tilt is due to the dispersive properties of equatorial beta-plane Rossby waves in which the lower meridional modes have larger amplitudes closer to the equator, and therefore propagate westward more quickly. As the northeasterly wind strengthens south of the high center, it streams southward, and after crossing the equator, it turns eastward between the equator and $15^{\circ} \mathrm{S}$. Panel B shows the solution three days later, in which the northeastsouthwest tilt becomes even more pronounced. To the southeast of the northeasterly surge streak, southwesterly cross-equatorial winds produce a wave (area d) as they swing back 
south to merge with the equatorial easterlies. The area between the surge streak and area $\mathrm{d}$ is a northeast-southwest-oriented counterclockwise circulation belt over the equator. The flow pattern (west of the equatorial easterlies) is mainly the manifestation of a dispersive Rossby wave group. The lower panels show the NOGAPS $850 \mathrm{hPa}$ wind analysis at the beginning of the actual cold surge (panel C; 0000 UTC 19 December), and three days later (panel D; 0000 UTC 22 December). Because of the narrow width of the South China Sea, the width of the intense surge belt is confined to about $750 \mathrm{~km}$, which is approximately one half of that in the equatorial beta-plane solution in panel $\mathrm{B}$ which is not subject to any terrain restriction. Thus, a comparison of the theory and the actual development may be made by scaling the eastwest dimension of the upper panels to one half of the original size $\left(\mathrm{L}=15^{\circ}\right.$ longitude instead of $30^{\circ}$ ), or treating the highlighted rectangular area in panels $\mathrm{A}$ and $\mathrm{B}$ as being comparable to the domain of the NOGAPS plots. The location of the high center in panel $\mathrm{B}$ was also shifted eastward by $0.4 \mathrm{~L}$ to account for the slower propagation due to the reduced zonal scale and two factors in real cold air outbreak events: the eastward movement of the East Asian surface high center due to the westerly mean flow, and the fixed location of the surge belt that is restricted geographically by the South China Sea.

\section{Concluding Remarks: Key Question Posed by Typhoon Vamei}

Since the observation of Typhoon Vamei, a number of modeling studies have successfully simulated this case of equatorial formation (e.g. Chambers and Li, 2007; Juneng et al., 2007; Koh, 2006). This is not surprising, since the interaction between the winter monsoon circulation and the complex terrain and the moisture from the warm ocean surface provided the vorticity and latent heat sources for development. However, the strong cold surge and Borneo vortex that led to the development of Typhoon Vamei are both regularly observed, major systems of the Asian winter monsoon in the South China Sea, and abundant low-level warm and moist air is present every winter. So the most interesting question is more than just how or why Typhoon Vamei could form so close to the equator, but rather, why more typhoon formation was not observed in the equatorial South China Sea.

Chang et al. (2003) postulated that the answer lies in the narrow extent of the equatorial South China Sea. Prior to Typhoon Vamei's formation, a strong cold surge persisted for nearly one week over the narrowing South China Sea, providing a source for background cyclonic vorticity as the surge wind crossed the equator. The anomalous strength and persistence of this surge was related to the anomalously strong meridional gradient of sealevel pressure in the equatorial South China Sea during December 2001 (Bureau of Meteorology Northern Territory Region, 2002). The narrowing of the South China Sea at the equator plays two counteracting roles that combine to make the occurrence of the typhoon formation possible but rare. On the one hand, the channeling and strengthening of the cross-equatorial surge winds helps to produce the background cyclonic vorticity at the equator. On the other hand, the open water region of approximately $5^{\circ}$ longitude is just sufficient to accommodate the diameter of a small tropical cyclone. However, it is too small for most synoptic-sized disturbances to remain over the water for more than a day or so. In the unusual case of Typhoon Vamei, the durations of the intense cold surge and the Borneo circulation remaining over water were both significantly longer than normal, which allowed the interaction to continue for nearly a week until the storm was formed.

In an analysis of the NCEP/NCAR reanalysis during the boreal winters of 
1951/52-2001/02, Chang et al. (2003) found that a total of 61 strong surge events lasting one week or more in the southern South China Sea occurred. The total number of days under these persistent surges is 582 . Assuming that the vortex needs at least a 3 -day overlap with the surge to develop, the sustained cyclogenesis due to a strong background relative vorticity is estimated to be present at the equator on about $10 \%$ of the boreal winter days. If the minimum persistent surge duration required is reduced from 7 days to 5 , the available time of the spinning top effect is increased to $14 \%$. During the 51 boreal winters, the frequency of a preexisting Borneo vortex staying over the equatorial water continuously for 4 days or more is 6 , or a probability of $12 \%$ in a given year. Whether a pre-existing disturbance develops into a tropical cyclone depends on background vertical shears of wind and vorticity, upper level divergence, and a variety of environmental factors (Anthes, 1982; McBride, 1995). In the more favored tropical cyclone basins of the western Pacific and North Atlantic, the percentage of pre-existing synoptic disturbances developing into tropical cyclones during their respective tropical cyclone seasons ranges between $10 \%$ and $30 \%$. Thus, of all the conditions that led to the formation of Vamei, Chang et al. (2003) estimated the probability of an equatorial development from similar conditions to be about once in a century or longer. This estimate appears consistent with the history of observations. However, it is not known whether other near-equatorial developments have occurred but were not observed during the presatellite era.

\section{Acknowledgements}

Interesting discussions were provided by H. Lim and S. L. Woon (Singapore); S. H. Ooi and Y. F. Hwang (Malaysia); C.-H. Liu and H.-C. Kuo (Taiwan); and R. Edson and M. Lander (Guam). This work was supported by ONR contract N0001402WR20302, NSF Grant ATM0101135 and the National Science Council/National Taiwan University.

\section{References}

Anthes, R. A., 1982: Tropical Cyclones: Their Evolution, Structure and Effects, American Meteorological Society Boston, 208 pp.

Chan, J., and C. Li, 2004: The East Asia winter monsoon. In East Asian Monsoon. C.-P. Chang (ed.), World Scientific Series on Earth System Science in Asia, Vol. 2, pp. 54-106.

Chambers, C. R. S., and T. Li, 2007: Simulation of a near-equatorial typhoon Vamei (2001). Meteorol. Atmos. Phys., 97, 67-80.

Chang, C.-P., J. E. Millard, and G. T. J. Chen, 1983: Gravitational character of cold surges during Winter MONEX. Mon. Wea. Rev., 111, 293-307.

Chang, C.-P., C.-H. Liu, and H.-C. Kuo, 2003: Typhoon Vamei: an equatorial tropical cyclone formation. Geophys. Res. Lett., 30, 1151-1154.

Chang, C.-P., P. A. Harr, J. McBride, and H. H. Hsu, 2004: Maritime Continent monsoon: annual cycle and boreal winter variability. East Asian Monsoon, C.-P. Chang (ed.), World Scientific Series on Earth System Science in Asia, Vol. 2, pp. 107-150.

Chang, C.-P., P. A. Harr, and H. J. Chen, 2005: Synoptic disturbances over the equatorial South China Sea and western Maritime Continent during boreal winter. Mon. Wea. Rev., 133, 489503.

DeMaria, M., and J. D. Pickle, 1988: A simplified system of equations for simulations of tropical cyclones. J. Atmos. Sci. 45, 1542-1554.

Fortner, L. E., 1958: Typhoon Sarah, 1956. Bull. Amer. Meteor. Soc., 39, 633-639.

Gray, W. M., 1968: Global view of tropical disturbances and storms. Mon. Wea. Rev., 96, 669700 .

Holland, G. J., 1984: On the climatology and structure of tropical cyclones in the Australian Southwest Pacific Region. Aus. Meteor. Mag., 32, 17-31.

Johnson, R. H., and R. A. Houze, Jr., 1987: Precipitating clouds systems of the Asian monsoon. In Monsoon Meteorology, C.-P. Chang and T. N. Krishnamurti (eds.), Oxford University Press, pp. 298-353.

Juneng, L., F. T. Tangang, C. J. Reason, S. Moten, and W. A. W. Hassan, 2007: Simulation of tropical cyclone Vamei (2001) using 
the PSU/NCAR MM5 model. Meteorol. Atmos. Phys., 97, 273-290.

Koh, T.-Y., 2006: Numerical weather prediction research in Singapore and case study of tropical cyclone vamei. In Winter MONEX: A Quarter Century and Beyond (WMO Asian Monsoon Workshop, 4-7 April 2006, Kuala Lumpur, Malaysia).

Lau, W. K.-M., and C.-P. Chang, 1987: Planetary scale aspects of winter monsoon and teleconnections. In Monsoon Meteorology, C.-P. Chang and T. N. Krishnamurti (eds.), Oxford University Press, pp. 161-202.

Lim, H., and C.-P. Chang, 1981: A theory for midlatitude forcing of tropical motions during winter monsoon. J. Atmos. Sci., 38, 2377-2392.

McBride, J. L., 1995: Tropical cyclone formation. In Global Perspective on Tropical Cyclones, R. L. Elsberry (ed.), Tech. Docu. 693, World Meteorological Organization, pp. 63-105. 